\title{
POLÍTICA DAS UPPS E ESPAÇOS ORGANIZACIONAIS PRECÁRIOS: UMA ANÁLISE DE DISCURSO
}

\author{
POLICIES OF THE UPPS AND TEMPORARY ORGANIZATIONAL SPACES: A DISCOURSE \\ ANALYSIS \\ POLÍTICA DE LAS UPP Y ESPACIOS ORGANIZACIONALES PRECARIOS: UN ANÁLISIS DE DISCURSO
}

\section{RESUMO}

O objetivo deste trabalho foi identificar as finalidades encobertas do programa de Unidades de Polícia Pacificadora (UPPs) e as intenções últimas a que serve, revelando, assim, as relações de poder e dominação a que estão submetidas as populações moradoras de espaços organizacionais precários, por meio do uso teleológico da política de pacificação de favelas do governo do Estado do Rio de Janeiro. Para tanto, foi utilizado o método de análise crítica do discurso na avaliação dos pronunciamentos realizados em um evento ocorrido na Câmara Municipal, em homenagem ao então coronel responsável pela coordenadoria de polícias pacificadoras. Os resultados desvelam a visão submissa com que os moradores de favela são tratados, orientando a política pública principalmente para a ocupação desses espaços e contenção dos problemas existentes nesse território, para que não sejam sentidos no restante da cidade.

PALAVRAS-CHAVE Análise de discurso, UPP, espaço, favela, territorialidade.

Daniel da S. Lacerda d.lacerda@lancaster.ac.uk

Pesquisador do Departamento Organization, Work and Technology, Lancaster University, Lancaster - Reino Unido

Vanessa Brulon vanessabrulon@gmail.com

Professora da Escola Brasileira de Administração Pública e de Empresas, Fundação Getulio Vargas - Rio de Janeiro - RJ, Brasil

Abstract The present work aims to identify the hidden goals and power relationships existing in the UPP Policy, disclosing the domination to which is subjected the population from precarious and fragile organizational spaces, such as slums, especially through the teleological use of Pacification Policy by the Government of Rio de Janeiro. Thus, we have performed a critical discourse analysis of the speeches given in a City Hall event, in honour of the colonel in charge of the pacification police. The analysis revealed a biased prejudicial image that figures in the statements when referred to slum dwellers, affecting the construction of public policies concerning the occupation of such territories, in order to isolate and take the issues of such territory apart from the rest of city.

keywords Discourse analysis, UPP, space, slum, territoriality.

Resumen El objetivo de este trabajo fue identificar los propósitos ocultos del programa de Unidades de Policía Pacificadora (UPP) y las intenciones ulteriores a que sirve, revelando, así, las relaciones de poder y dominación a que están sometidas las poblaciones habitantes de espacios organizacionales precarios, por medio del uso teleológico de la política de pacificación de villas de emergencia del gobierno del Estado de Rio de Janeiro. Para ello, fue utilizado el método de análisis crítico del discurso en la evaluación de los pronunciamientos realizados en un evento ocurrido en la Cámara Municipal, en homenaje al entonces coronel responsable por la coordinaduría de las policías pacificadoras. Los resultados revelan la visión de subyugación aplicada a los habitantes de las villas de emergencia, orientando la política pública principalmente hacia la ocupación de esos espacios y contención de los problemas existentes en ese territorio, para que no sean sentidos en el resto de la ciudad.

Palabras clave Análisis de discurso, UPP, espacio, villa de emergencia, territorialidad. 


\section{INTRODUÇÃO}

A aplicação dos estudos organizacionais considerando seus contextos espaciais possibilita a investigação dos antecedentes e consequentes que formam o espaço organizacional (e.g., GOULART e outros, 2010; VERGARA e VIEIRA, 2005). Além disso, a aproximação com o referencial que trata do espaço geográfico, bem como de seus conceitos correlatos, conforme mostrou Goulart (2006), possibilita uma ampliação do nível de análise, sem que se perca o foco nas organizações e em suas interações. Um problema de fundamental importância da gestão do espaço/território, e que assola todos os países, embora se dê de maneira mais intensa em países subdesenvolvidos, é a formação de favelas, fenômeno associado à pobreza urbana. Regiões marcadas por informalidade, as favelas sempre foram uma solução de moradia para a população pobre, que não pode arcar com os altos aluguéis da cidade, mas se tornaram também um problema, em função das condições precárias e instáveis de moradia e ocupação da cidade.

Este trabalho parte do pressuposto de que as precariedades e limitações de um espaço degradado como a favela acontecem por causa da dominação exercida por estruturas sociais. A política de pacificação das favelas do Rio de Janeiro, por meio do programa das UPPs (UPPRJ, 2011), com a consequente instalação de organizações do poder público nessas localidades, porquanto possa ter intenções justas de promover a presença do Estado em áreas antes tomadas por poderes paralelos, pode ser usada indevidamente como apenas mais um instrumento de controle social. Tendo em vista que o território é lócus de relações de poder, e é definido por e com base nessas relações (SOUZA, 2002), é imperioso que se investiguem as relações de poder e dominação que se estabelecem nos espaços precários das favelas, decorrentes da recente política de pacificação, para que também se tragam à luz as transformações territoriais que ali ocorrem.

Em 2011, um vereador da cidade do Rio de Janeiro, propôs e aprovou em plenário uma homenagem ao então coronel responsável pela coordenadoria de polícias pacificadoras, com o oferecimento da medalha Pedro Ernesto. A medalha foi entregue em 5 de setembro de 2011. Estiveram presentes cerca de 200 militares, entre oficiais e praças, além de alguns familiares e amigos do coronel, e cerca de 40 crianças de duas organizações beneficentes do morro do Cantagalo, acompanhados dos responsáveis pelo grupo. Nenhum outro vereador ou membro do poder legislativo esta- va na casa. A homenagem, que contou também com intervenções do público, projeção de vídeos, músicas e entregas de placas aos policiais, foi uma celebração efusiva. A pergunta subjacente a tal homenagem, feita a um militar que comanda o programa de UPPs, por mais honroso, competente e bem-intencionado que ele possa demonstrar ser, é: por quê?

O coronel Robson Rodrigues da Silva, que antes estava à frente da Coordenadoria de Análise Criminal, foi o escolhido para assumir o Comando de Polícia Pacificadora (CPP), responsável pelas UPPs, em 2010. $\mathrm{O}$ vereador que promoveu a homenagem, eleito como suplente de outro vereador que se afastou para assumir a secretaria municipal de obras, em janeiro de 2009, era o então vice-presidente da Comissão de Turismo da Câmara, e o cargo ocupado por ele foi motivador de uma análise mais criteriosa daquele evento, estudado neste trabalho.

Diante dessas inquietações, o objetivo da presente investigação é identificar as finalidades encobertas do programa de UPPs e as intenções últimas a que serve, por meio da investigação de dois discursos proferidos no evento supracitado. Com isso, esperamos desvelar as relações de poder e dominação a que estão submetidas as populações moradoras de espaços organizacionais precários, com base no uso teleológico da política de pacificação de favelas do governo do Estado do Rio de Janeiro. A perspectiva teórica e os fundamentos conceituais que norteiam o trabalham seguem a proposta de autores como Marcelo Milano Falcão Vieira e Sueli Goulart, que enfatizam e demonstram a importância de se inserirem nos estudos organizacionais as temáticas de espaço e território, de modo a se assumirem as organizações como configuradoras e configuradas por e a partir do território no qual estão inseridas (e.g., VIEIRA e VIEIRA, 2003; GOULART e outros, 2010).

\section{REFERENCIAL TEÓRICO}

Visando a apreender o fenômeno dentro da sua complexidade, será realizada aqui uma articulação do objeto estudado com três categorias principais: espaço, favelas e políticas públicas de segurança.

\section{Estudo do espaço}

Como o escopo desta pesquisa está orientado ao estu- 
do de espaços precários, é importante também considerar suas especificidades com base na aproximação da categoria espaço, visando entender e justificar a forma de existência e atuação de organizações que ali estejam. A categoria espaço - e seus conceitos correlatos, como território, lugar, ambiente etc. - é fundamental para investigações em estudos organizacionais que considerem verdadeiramente o contexto social de entorno. Assim como na Física, essa categoria é operacionalizada a partir do conjunto tempo-espaço, que representa as diferentes escalas de desenvolvimento social. Sua utilização é importante na medida em que provê um pano de fundo às demais categorias de pesquisa: "é no tempo-espaço que estruturas, processos, tomadas de decisão, modelos de gestão, tecnologias, poder, enfim as tradicionais categorias de análise ocorrem" (VERGARA e VIEIRA, 2005).

O conceito traz, ainda, contribuições para se pensarem políticas públicas. A noção de território classicamente utilizada para produção de políticas públicas é, muitas vezes, banalizada e usada como sinônimo de um espaço qualquer, sobre o qual são aplicadas políticas públicas que se inspiram em modelos exógenos (GOULART e outros, 2010). Para Goulart e outros (2010, p. 389), "a exploração de construtos, conceitos e categorias de outras áreas disciplinares, particularmente da geografia, oferece importantes e consistentes elementos para a formação e para a investigação de políticas públicas direcionadas ao desenvolvimento". Além disso, as investigações a respeito das relações de poder e dominação em estudos organizacionais, como a que aqui se propõe, tendem, muitas vezes, a analisar essas relações descoladas do território no qual se estabelecem, negligenciando a influência e a inseparabilidade entre poder e território. Ao incorporar a concepção de espaço geográfico, assumem-se também as organizações como reconfiguradoras do território, e sua interferência nesse sentido passa a ser considerada.

A apreensão holística dos acontecimentos sociais, que, de acordo com o paradigma espaço-tempo, só pode ocorrer com base nessa abordagem dual, para além da dicotomia objetivo-subjetivo, é frequentemente reduzida à subordinação de tais acontecimentos à busca estratégica de eficiência. Nessa perspectiva, espaço é mais comumente representado pelo conceito "ambiente", no qual são isoladas variáveis que dão indicações estratégicas do resultado desejado. Mas, como mostram Vieira e Garrofé (2005), uma reflexão da forma e do contexto é essencial até mesmo na apreciação de técnicas de gestão e modelos econômicos e sociais, de modo que não seja empreendida uma manipulação do sentido do tempo e do significado do espaço.

Milton Santos foi um notório pesquisador do espaço e do território. Para o autor, "a arena da oposição entre o mercado - que singulariza - e a sociedade civil - que generaliza - é o território, em suas diversas dimensões e escalas" (SANTOS, 2009). O mesmo autor propõe que o espaço geográfico seja assumido como uma categoria de análise social. Para ele, espaço é definido como o "conjunto indissociável, solidário e também contraditório, de sistemas de objetos e sistemas de ações, não considerados isoladamente, mas como o quadro único no qual a história se dá" (SANTOS, 2009, p. 63). Baseado em sua definição, Santos (2009) reforça a ideia de que os sistemas de objetos e os de ações não podem ser pensados um sem o outro (um conjunto de 'fixos' e 'fluxos'). Os sistemas de objetos dão forma às ações, e os sistemas de ações criam novos objetos. Eles interagem e, por meio dessa interação, o espaço se transforma.

Para as ciências sociais, o conceito de espaço só adquiriu sentido mais estrito a partir da distinção do conceito de território. Embora sejam diversas as definições de território, elas geralmente marcam sua inter-relação com o poder, tendo em vista que o território é lócus de relações de poder, e é por elas reconfigurado (SOUZA, 2002). Os territórios são, assim, espaços de ação e de poderes (NEVES, 2002), "a cena do poder e o lugar de todas as relações" (RAFFESTIN, 1993, p. 58), e também podem ser entendidos como conflito social (DEMATTEIS, 2007). Ou, como aponta Castro (2003), o território deve ser entendido como uma arena de disputa de interesses, constituído por relações políticas, onde as noções de poder e de controle encontram-se intrinsecamente incorporadas.

Raffestin (1993) explica que o território revela relações de poder. A produção do território está perfeitamente inscrita no campo do poder, tendo em vista que as estratégias de produção elaboradas por esses atores chocam-se umas com as outras em diversas relações de poder (RAFFESTIN, 1993). Nesse sentido, segundo o autor, todas as relações que se estabelecem em um território são relações de poder, queo se torna inevitável, impossível de se fazer ausente em qualquer relação. A partir das relações de poder, a ação humana afeta a materialidade do território, e os dois elementos apresentados por Santos (2009) tornam-se 
relacionados e indissociáveis, produzindo-se novas configurações territoriais.

Tendo em vista que o território é produzido com base nas relações de poder que nele se estabelecem, a importância de se investigarem as relações de poder para a compreensão da reconfiguração do território é destacada por muitos autores na literatura (exs: SOUZA, 2002; RAFFESTIN, 1993; BRANDÃO, 2007). Vieira e Vieira (2003, p. 103-108), especialmente, alertam para a crescente influência que o poder econômico exerce no poder político do Estado. É nesse sentido que a investigação que aqui se propõe incorpora as categorias de espaço e território, visando observar as influências de poder exercidas sobre elas.

\section{A questão das favelas}

Espaços precários não são vistos aqui somente da perspectiva do que não possuem, mas também observando-se as características que lhe são peculiares e as consequências dessas características para estudos organizacionais e sociais. Um forte símbolo de espaços precários no Brasil, as favelas representam a destinação de muitos projetos sociais e a origem de muitas iniciativas. O Observatório de Favelas (2009), uma ONG orientada para a pesquisa, ressalta, entre as características desses espaços, a "apropriação social do território" (p. 22), como também "relações de vizinhança marcadas pela intensa sociabilidade" (p. 23).

Aproximadamente $20 \%$ da população mundial vivem em favelas (DELICATO, 2007). No Brasil, os censos do IBGE mostram que a população moradora de favelas cresce mais do que a população urbana (MARICATO, 2007). Segundo Denaldi (2005), nos principais centros metropolitanos do País, de 20 a $40 \%$ da população total reside em favelas. Entretanto, Maricato (2001) lembra que esses dados podem não ser precisos, já que é difícil classificar corretamente muitas das favelas sem que os cadastros municipais sejam acessados, e defende que, provavelmente, a população que mora em favelas é bem maior do que prevê o IBGE.

A acelerada disseminação de favelas no Brasil teve início no fim do século XIX, quando foi formada a primeira aglomeração urbana que recebeu esse nome, na cidade do Rio de Janeiro, no Morro da Providência. Como foi fundada por antigos combatentes da Guerra de Canudos, a região recebeu o nome de "favela" em referência ao local onde os seguidores de Antônio Conselheiro se encontravam, no sertão baiano (OLIVEIRA, 1985). Segundo Oliveira (1985), a partir daí, todas as aglomerações semelhantes que surgiram também receberam esse nome. No início do século XX, as favelas começaram a se expandir e a se tornar "visíveis" (OLIVEIRA, 1985). Pino (1998) alega que problemas como inflação, desemprego, bem como altos preços de aluguéis, foram as principais causas desse quadro social. Agravado pela tendência migratória para centros urbanos, o crescimento das favelas acelerou-se, e, em 1950, 7\% da população total da cidade do Rio de Janeiro moravam em favelas (OLIVEIRA, 1985).

Como mostra Strozemberg (2009), as favelas são historicamente identificadas como a expressão de antítese da ordem pública, como um espaço transgressor, sem leis ou, pelo menos, sem as mesmas leis que regem o restante da cidade. Mas a ausência de uma equivalência de leis também implica a ausência uma equivalência de direitos e, principalmente, a ausência de um direito superior, que Lefebfre (2001, p. 134) chama de direito à cidade, entendido como "O direito à liberdade, à individualização na socialização, ao habitat e ao habitar", que acaba por se constituir como um direito mal reconhecido, diante de outros problemas urbanos.

Embora tenham surgido como forma de solução imediata para um problema urbano de habitação da população mais pobre, em um cenário de elevação de preços dos solos, as favelas tornaram-se um dos principais problemas urbanos, na medida em que foram se expandindo. Com sua disseminação, a favela passou a ser enxergada como um "problema" social que precisava ser combatido (OLIVEIRA, 1985). Segundo Valladares (2000), no início do século XX, o "problema" das favelas passou a ser discutido por jornalistas, médicos e engenheiros que demonstravam preocupação com o futuro da população, acendendo um debate em torno do que fazer com elas. E esse debate ganhou importância ainda maior, na medida em que a favela tem sido símbolo de outro grave problema social: a falta de segurança pública. Com a ausência do Estado nesses espaços, o poder paralelo do tráfico de drogas dominou-os.

No Brasil, merece destaque a relevância da questão na cidade do Rio de Janeiro, local em que foi formulado o maior número de políticas governamentais voltadas para as favelas (VALLADARES e FIGUEIREDO, 1983). Como mostrou Valladares (2000), a expansão das favelas cariocas pode ser percebida, por exem- 
plo, observando-se o caso da Rocinha, localizada em São Conrado, que, entre as décadas de 1970 e 1980, aumentou sua população em mais de um terço e teve seus muitos imóveis valorizados (OLIVEIRA, 1985). Assim, o Rio de Janeiro acabou se tornando o principal objeto de análise da maioria dos trabalhos que discutem a origem e a expansão das favelas (COSTA e NASCIMENTO, 2005).

\section{Políticas públicas de segurança}

Segundo Secchi (2010, p. 1), as políticas públicas "tratam do conteúdo concreto e do conteúdo simbólico de decisões políticas, e do processo de construção e atuação dessas decisões". Para Souza (2006, p. 26), a política pública pode ser pensada como "o campo de conhecimento que busca, ao mesmo tempo, 'colocar o governo em ação' e/ou analisar essa ação (variável independente) e, quando necessário, propor mudanças no rumo ou curso dessas ações". Souza (2006) acrescenta que, embora existam diferentes definições de políticas públicas, a maioria delas assume uma visão holística.

Villanueva (1992) observa, ainda, que há duas posições extremas no que se refere à natureza e às ferramentas de análises das políticas. De um lado, está a visão racional estrita da análise política, que pode até reconhecer a existência de diversas e poderosas restrições, mas sem renunciar à exigência de racionalidade como base fundante da sua formulação e decisão. De outro lado, está uma visão negociadora e pragmática da política, que considera a análise uma condição insuficiente e, em alguns casos, desnecessária para sua decisão e desenvolvimento. Sob esse olhar, a política das UPPs deve ser considerada a partir da conceituação do seu ciclo, que é aproximado ora pela intelectualização de suas análises e formulação de estratégias de ocupação, ora pelo desprezo às análises em defesa de uma decisão pelo arranjo de poderes entre os vários atores sociais envolvidos.

As políticas públicas de segurança vêm ganhando destaque em um momento em que o aumento dos índices de violência torna-se preocupante no Brasil. A segurança pública, alcançada quando o Estado fornece garantia e preservação dos direitos e liberdades individuais, é tida como um direito social vital (XAVIER, 2008). Para Soares (2003, p. 89), segurança significa "estabilidade de expectativas positivas, compatíveis com a ordem democrática e a cidadania, envolvendo, portanto, múltiplas esferas formadoras da qualidade de vida".

Conforme explica Beato Filho (1999), a dificuldade de se desenvolverem políticas públicas de segurança está no fato de que há uma divergência em relação ao que se acredita que seja a origem do crime. Enquanto alguns atribuem ao problema uma causa socioeconômica, outros o pensam como uma questão de polícia e de legislação mais repressivas. A esse respeito, Soares (2003) defende que as duas coisas não devem ser pensadas como dicotômicas. Para o autor, a política pública de segurança deve se preocupar tanto com a reforma das estruturas sociais quanto com as dinâmicas da violência.

Mesmo diante das dificuldades citadas, tendo em vista a perda de poder público para o tráfico nas favelas da cidade do Rio de Janeiro, o Governo do Estado implementou, a partir de 2008, um modelo de segurança: as UPPs. O decreto legal que define a estrutura do programa de UPPs (três anos após sua criação) define como objetivos "consolidar o controle estatal sobre comunidades sob forte influência da criminalidade" e "devolver à população local a paz e a tranqüilidade públicas" (RIO DE JANEIRO, 2008). Ressalta-se, ainda, a expectativa provocada por essa estratégia de segurança de fortalecer as ações sociais nas favelas, tendo em vista a inclusão de seus moradores, apesar de se tratar de um programa da Secretaria de Segurança Pública. Esse imaginário se dá pelo reconhecimento de que a questão das favelas não pode ser tratada apenas por ações de polícia.

Qualquer definição de agenda para a questão das favelas no Rio de Janeiro deveria partir sempre do problema mais abrangente, e também de sua causa raiz - evitando o que Bardach (1993) chama de subótimo do problema, nesse caso, a ausência do Estado nesses territórios. Essa ausência, que leva Silva (2011) a chamá-los de "não Estado" (p. 5), conduziu a uma fragilização e consequente precarização dos serviços públicos para essa população. Por esse motivo, a questão das favelas não deveria ser tratada apenas como um problema de segurança pública. Conforme defende Strozemberg (2009), para que haja uma verdadeira integração da favela à cidade, é preciso haver uma incorporação de direitos por parte de seus moradores. De uma política de Estado, espera-se um reconhecimento da igualdade de direitos em primeiro lugar, que garanta o acesso irrestrito à cidadania concreta. 
E garantir cidadania concreta implica o reconhecimento do território favelado como território constituído por cidadãos corporificados de direito. Sendo assim, práticas como as que vêm sendo observadas, como a militarização do território e o controle social compulsório, vão na contramão do que se esperava com a chegada das UPPs, no tocante a uma política de aproximação e o estabelecimento da favela como parte indissociável da cidade (SILVA, 2011, p. 23).

\section{MÉTODO}

Para investigar as falas do evento que motivaram a presente avaliação, foi empreendida uma análise crítica do discurso, com base nas transcrições realizadas em trechos escolhidos desses pronunciamentos.

\section{Análise do discurso}

Entre os discursos realizados em plenário no dia da homenagem anteriormente apresentada, foram escolhidos dois trechos para análise: o discurso de abertura do vereador, feito da mesa diretora, e uma declaração de seu assessor, feita do palanque do plenário. Os textos transcritos foram avaliados utilizando análise do discurso, conforme procedimento descrito por Fairclough (2001). A riqueza do discurso como foco da análise dá-se porque ele é, ao mesmo tempo, um constituinte social - pois é uma das formas com que as pessoas podem agir sobre o meio - mas, também, uma representação desse mesmo meio - pois reflete as entidades e relações sociais existentes ali (MAGALHÃES, 2001). O discurso é, portanto, mediador e constituinte da prática linguística e social.

Uma função marcante que essa técnica oferece aos estudos sociais aplicados é a capacidade de proporcionar uma visão crítica das organizações, assim como defendido por Vieira e Caldas (2006). A análise do discurso não é um método único e não tem nem mesmo uma única perspectiva epistemológica de análise. Fairclough (2001) divide as abordagens de análise de discurso, segundo a natureza da orientação social para o discurso, em "não críticas" e "críticas". As abordagens críticas diferenciam-se por mostrarem como o discurso é moldado por relações de poder e ideologia. Dentro do que o autor considera as abordagens críticas, está a sua própria proposta de abordagem. Fairclough (2001), estendendo o esquema linguístico de Michael Halliday, estuda a manifestação do discurso em três dimensões sobrepostas: texto, prática discursiva e prática sociocultural. A combinação desejada pelo autor é uma análise que leva em conta a relevância e especificidade social como instrumentos e reflexos da mudança social, além de ser um esquema metodológico para a análise.

\section{Transcrição e codificação}

Foram transcritos dois pronunciamentos: 1. discurso de abertura do vereador, que presidia a sessão, iniciado após a apresentação dos membros da mesa e da execução do Hino Nacional pela banda da PM; 2. pronunciamento do assessor do vereador durante homenagem, após o discurso de abertura, tendo sido o quinto orador inscrito. Os dois textos foram transcritos, e um trecho de cada um deles é mostrado a seguir. Foi utilizada a seguinte legenda:

\section{[ênfase]} Pausa

.... Pausa longa

$\% \%$ Momento de estresse

$\wedge \wedge \wedge$ Respirações

\{Fulano: nnnnnnn\} Sobreposição de voz do fulano

??? Hesitação

XXX Não compreensível

\#\#\# Nome omitido

\section{Fragmento de texto 1 ( $8 \mathrm{~m} \mathrm{33s)}$}

[...] A partir de hoje, cel. Robson, o seu nome também faz parte da história desta casa de leis. Este parlamento é o espelho da nossa sociedade ___ e aqui estão os representantes do povo carioca. Essa é uma homenagem que estou fazendo ao senhor, cel. Robson, e a toda a equipe das UPPs, acredito que seja a homenagem mais merecida, justa, oferecida por um parlamentar ___em todo o nosso país___ nos últimos dois anos. Quais os brasileiros ??? que merecem mais aplausos no ano de 2010 e de 2011? Na minha opinião, e da maioria dos cariocas, [não tenho a menor dúvida], são todos aqueles que foram e são responsáveis pela implantação do sucesso das UPPs. Já que a paz nas ruas no Rio era algo [inimaginável]. [...]

\section{Fragmento de texto 2 ( $2 \mathrm{~m} 28 \mathrm{~s})$}

[...] Nosso último ato aqui. Boa-tarde, boa-tarde, coronel. Eu falo aqui, acho que em nome, representando, acho que duas classes, vamos dizer assim: uma 
como o gabinete do vereador Marcelo Arar, e __ a tranquilidade que as UPPs deram pra projetos novos, a coordenação de turismo da cidade, que é uma coisa fundamental, que mexeu muito, que facilitou muito até o nosso trabalho [...]

São mostrados, a seguir, os códigos definidos e um exemplo de identificação para cada um deles, conforme análise preliminar do discurso (FAIRCLOUGH, 2001):

- Relevância do ato: "A medalha Pedro Ernesto que nosso homenageado está recebendo hoje é a mais alta [honraria] que o poder municipal pode dar para uma pessoa";

- Autoridade: "Este parlamento é o espelho da nossa sociedade ___ e aqui estão os representantes do povo carioca";

- Pessoalidade: "Essa é uma homenagem que estou fazendo ao senhor, cel. Robson";

- Exaltação: "Os nossos heróis, os nossos campeões";

- Segregação: "o povo que morava em uma terra sem leis";

- Transformação: "vamos poder dizer que a cidade do Rio de Janeiro foi dividida em dois períodos: [antes] das UPPs e [depois] das UPPs";

- Controle: "Obrigado por devolverem aos cariocas parte da cidade que tínhamos perdido" (vereador).

\section{ANÁLISE DOS DADOS}

A análise realizada conforme Fairclough (2001) está apresentada aqui seguindo o próprio esquema analítico do autor, dividido em análise textual, análise da prática discursiva e análise da prática social.

\section{Análise textual}

Segundo Fairclough (2001, p. 98-100), a análise textual é importante na medida em que a prática discursiva manifesta-se em forma linguística. Ela é, portanto, de natureza descritiva, apesar de poder conter elementos discursivos interpretativos.

Em relação à estrutura textual, o primeiro pronunciamento pode ser dividido em quatro partes principais e sobrepostas. A primeira versa sobre a importância da homenagem que está sendo realizada; a segunda, sobre a importância do coronel home- nageado; a terceira, sobre a relevância do programa de UPPs; e, por fim, a transformação ocorrida na cidade. As orações, portanto, intercalam-se em termos de sentido nos três trechos finais. O segundo texto analisado é mais desestruturado, mas podem ser identificadas duas temáticas no pronunciamento do orador: a visão como assessor do vereador e a visão de empresário. Ambos os discursos buscam, de maneira muito polida, posicionar-se em um nível de cortesia que retrate o ambiente formal que rodeia o evento. O contexto traz em si, portanto, um ethos particular, que pode ser observado na forma honrosa como os indivíduos objetos das orações são referidos ("representantes do povo", "senhores", "honraria", "espelho da cidade", "corporação"), apesar das inserções coloquiais intencionais.

O primeiro pronunciamento mistura um vocabulário culto, comumente encontrado em discursos, com neologismos criados pelo orador (ex: "o quadrante de enorme necessidade"). Já o segundo é pobre no volume vernacular e traz um processo de lexicalização muito próximo ao coloquial. Chama a atenção o uso de algumas palavras que dão o sentido de epopeia ao feito descrito, como "missão"; "é o cara"; "heróis"; "campeões", bem como o uso de vocábulos com uma significação depreciativa para se referir às favelas: "selva urbana"; "massacrada"; "oprimida".

No que diz respeito à gramática, a transitividade das orações do texto mostra investimentos ideológicos nas afirmações diretas e orações declarativas, por exemplo: "A maioria das leis que rege nosso município sai daqui"; "Já que a paz nas ruas no Rio era algo inimaginável"; "Eu tenho duas casas noturnas e as duas aumentaram o movimento". Essas declarações não aconteceram apenas na forma declarativa. Na frase "o orgulho de não se ouvir mais falar em arrastão" (assessor), a negação carrega um tipo especial de proposição (cf. FAIRCLOUGH, 2001, p. 157) de que as comunidades não pacificadas geravam arrastões na cidade.

Apesar de o primeiro trecho representar um discurso, há pouca coesão nos pedaços que se intercalam, que são mais ligados pela repetição de palavras como "UPPs" e "cel. Robson" do que por mecanismos de referência ou conjunção. O segundo trecho é ainda menos coeso, provavelmente por se tratar de fala improvisada, e só mostra ligação a partir da introdução do texto.

\section{Análise da prática discursiva}

Para Fairclough (2001), a análise do discurso como 
prática discursiva focaliza os processos de produção, distribuição e consumo textual, que exigem uma contextualização institucional, econômica e política para serem corretamente interpretados.

Embora o vereador se coloque, em muitos momentos, como representante dos cidadãos cariocas, como no trecho "Na minha opinião, e da maioria dos cariocas, [não tenho a menor dúvida], são todos aqueles que foram e são responsáveis pela implantação do sucesso das UPPs"; também se pode perceber passagens fundamentadas em uma percepção bastante pessoal ("eu olhei para um assessor meu, \#\#, e falei: o cel. Robson [é o cara]! Desde então resolvi que tinha que homenagear esse homem e toda a sua equipe"). Por trás da homenagem realizada, há um discurso político. O vereador fala como representante de seu partido político e, ao realizar sua homenagem, está, também, legitimando uma política de segurança pública posta em prática pelo mesmo governo do Rio de Janeiro que estava no poder na ocasião (do PMDB) e que recebia seu apoio.

O controle do discurso pelo vereador é evidenciado pela subjetividade com que se coloca (ex: "Essa é uma homenagem que estou fazendo ao senhor"). E esse controle é também alternado dialeticamente com um distanciamento que lhe permite ter esse controle, por meio da manipulação de um metadiscurso (exs: "Dentro de longo tempo, vamos poder dizer que a cidade do Rio de Janeiro foi dividida em dois períodos"; "Toda a nossa sociedade independente de sua paz social, cultural e econômica tem o dever de aclamar todos esses policiais").

A distribuição do texto dá-se por meio das cadeias intertextuais nele presente. Nesse caso, as cadeias revelam um ambiente institucional, caracterizado pela formalidade dada pela natureza do evento, e um contexto marcadamente político. Além disso, trata-se de um consumo coletivo, em função da natureza política do evento. Quanto ao trabalho inferencial requerido para interpretação do texto, o investimento destinado à interpretação por parte daqueles que consomem o discurso não carece de grande complexidade. Com efeito, ambos os discursos possuem um alto grau de precariedade, já que não são suficientemente fundamentados, e não fazem muitas referências a eventos passados, que gerem a necessidade de conhecimentos prévios para a interpretação do texto.

O gênero dos textos, especialmente o discurso de vereador, pode ser associado com o processo particu- lar de produção, distribuição e consumo de discursos ocorridos em plenários de casas públicas do legislativo, seguindo um ethos especial e muito particular. Pode-se citar, entre as características: a polidez do orador, a abertura protocolar, o tom exaltado de proclamação, o ambiente formal do plenário, representado pelos trajes e posturas dos presentes, as reações da plateia em momentos específicos, as tomadas de turno, que só ocorrem após o final com a concessão do orador, o estilo expositivo e oficioso, entre outras. Esses elementos favorecem a determinação social pelo discurso produzido.

A produção pode ser pensada como coletiva, na medida em que o vereador fala em nome do seu partido político e de parcela da sociedade que o elegeu. Entretanto, ela também é confessadamente motivada por questões individuais, na medida em que o vereador explicita sua decisão pessoal de realizar a homenagem com base em percepções próprias. E, para além das locuções manifestadas, existem também elementos não ditos que corroboram as intenções pessoais de produtor do discurso, como será visto na seção a seguir.

\section{Análise da prática social}

As pessoas do animador, autor e principal são as mesmas, representadas pelo vereador e seu assessor. Os consumidores desse discurso são o homenageado e os cidadãos cariocas presentes, mas também aqueles não presentes, que são atingidos indiretamente pelo discurso do evento. A prática discursiva foi moldada pelas ordens de discurso, já que o vereador e seu assessor legitimam, por meio de seus pronunciamentos, uma lógica civilizatória.

No que diz respeito à matriz social, o discurso sobre favelas corrobora as estruturas e relações sociais hegemônicas que estão por trás dele. É um discurso que legitima uma política de segurança implantada em tempos recentes, nesse caso, reforçando as relações de poder existentes. Além disso, insinua a existência de uma sociedade homogênea, em que há uma unidade de pensamento no que tange aos benefícios da política de segurança. Por meio de seus discursos, o vereador e seu assessor corroboram uma visão conservadora, que vê as favelas como uma "selva urbana", na qual as pessoas apenas adquirem dignidade depois de uma intervenção externa. Ex: "Não existia missão mais adequada para entrar numa comunidade, até então não pacificada, uma verdadeira selva urbana... que 
um antropólogo, um especialista em seres humanos. Pra entender, pra abraçar, pra estender a mão, dando cidadania e dignidade e pra tomar conta de um povo que morava em uma terra sem leis".

Quanto aos efeitos ideológicos e políticos do discurso, fica claro que os pronunciamentos analisados, especialmente o primeiro, estão fundamentados em uma visão ideológica de mundo particular. Para essa visão, de um lado, estão pessoas destituídas de sua dignidade e cidadania, no interior das comunidades ou selvas urbanas, como o vereador as designa. Essa dignidade só pode surgir com uma intervenção por parte de indivíduos localizados fora dessa mesma "selva". Tal discurso revela uma visão de progresso verticalizado. Também é revelador o trecho em que se menciona a importância de que um antropólogo seja o principal interventor da comunidade, o que enfatiza uma visão de extremo estranhamento e distanciamento por parte do orador quanto a um modo de vida "exótico", que apenas poderia ser compreendido por um profissional especializado.

O discurso é imbuído de autoridade (ex: «em nome do poder legislativo do município do Rio de Janeiro e do povo carioca") e relevância ("A partir de hoje, cel. Robson, o seu nome também faz parte da história desta casa de leis"). A ele, é adicionado um conteúdo muito particular, densamente estruturante: as UPPs, como organizações do poder público, "resolvem" o "problema" de segurança da cidade por meio da "pacificação" de comunidades que antes eram "selvas urbanas" e usurpavam a autoridade formal do Estado, utilizando-se desse poder para cometer crimes (e "arrastões") em toda a cidade.

Para o vereador e sua equipe, sensibilizados e ligados às iniciativas de fomento ao turismo na cidade, a UPP, de fato, foi uma solução. Essa opinião é mostrada na articulação do discurso pronunciado: as UPPs controlam ("Lugares esses onde, antes das UPPs, não tinha justiça, não tinha governador, não tinha prefeito nem polícia") as comunidades especiais ("Os policiais das UPPs, que sabem a forma especial de agir e de atuar com aquela determinada população") para que os efeitos colaterais de sua exclusão não atinjam o restante da cidade ("O orgulho de não se ouvir mais falar em arrastão"). Essa transformação ocorrida ("vamos poder dizer que a cidade do Rio de Janeiro foi dividida em dois períodos: antes das UPPs e depois das UPPs") é suficiente para atender aos seus interesses ("a gente tem uma cidade que tem segurança pra receber a
Copa do Mundo, as Olimpíadas, e vários outros eventos"). Nada é dito da vida das comunidades, que tem como efetivo problema a carência da presença real do Estado.

\section{CONSIDERAĢÕES FINAIS}

\section{Territorialidade das organizações}

A territorialidade de espaços de favela pressupõe a ocupação e significação desses espaços por meio da sua utilização pelo homem. Uma apropriação que pressupõe relações sociais contínuas, sem rupturas no espaço social. Mas tal continuidade é rompida pela evidência de uma cidade partida nos depoimentos aqui apresentados. Com base na análise dos discursos, mostrou-se uma visão civilizatória como pano de fundo, que parte primeiramente da crença na necessidade de uma intervenção externa e superior para reestabelecer a dignidade dos moradores das favelas e a recuperação do espaço da cidade, que é afetado pelos crimes que saem do espaço de favela. Tal constatação mostra que a lógica excludente e a noção de "pedagogia civilizatória" que marcaram, conforme os relatos de Burgos (2002), as políticas públicas voltadas para as favelas ao longo da história ainda se fazem presentes. Com base na crença de que os moradores das favelas vivem em uma "selva urbana" e delas precisam ser salvos, é mais fácil justificar a entrada de organizações do poder público como as UPPs, que apresentam novos mecanismos de controle do Estado sobre a sociedade como solução do problema.

Nota-se, ainda, o fato de que o vereador que promoveu a homenagem é vice-presidente da Comissão de Turismo da Câmara. Advinda dessa comissão, a homenagem tem por base benefícios que a nova política de segurança pública pode trazer para aqueles que não habitam a "selva urbana" das favelas, mas apenas sofrem as consequências de sua desordem. Uma evidência que aponta nessa direção é que, especialmente nas primeiras unidades implantadas, as favelas escolhidas para acolherem essas unidades estão em regiões ricas e turísticas (exs: Ipanema, Copacabana, Botafogo), ou de acesso a essas zonas(exs: Santo Cristo, Jacarepaguá, Estácio).

Ao se pensarem as favelas como espaços, com base no que foi proposto por Santos (2009), consideram-se esses locais como compostos por 'fixos' e 'fluxos', sistemas de objetos e sistemas de ações, indissoci- 
áveis, que geram transformações por meio da interação que estabelecem entre si. Novas organizações que se inserem nesses espaços trazem mudanças nas relações de poder que ali se estabelecem, componentes de seu sistema de ações, e, consequentemente, afetam seus sistemas de objetos. Assim, o território assume uma nova configuração, que pode conter transformações sociais, das quais as favelas tanto carecem. No entanto, há indicadores no discurso analisado que apontam que essas transformações ocorrerão visando apenas a benefícios econômicos externos.

Vieira e Vieira (2003) mostram que as estratégias globais definem uma nova geoestratégia espacial, na qual "o econômico está triunfante, enquanto que o social passou à categoria subalterna". Ao pensar o espaço em toda sua dimensionalidade, as políticas públicas deveriam recuperar as dimensões social e política que se perderam, mas não foi isso que observamos. A presença das UPPs no espaço das favelas impõe uma nova configuração a esse território. Os mecanismos de dominação do Estado sobre essa parcela da sociedade, que antes vivia sob o poder do tráfico, ampliam-se, mas a segurança almejada é para outra parcela da sociedade. As possíveis transformações sociais que a entrada de novas organizações no espaço das favelas poderia trazer podem acabar se perdendo, diante do foco nos benefícios para a segurança fora do espaço da favela. Esse fenômeno foi descrito por Santos (2009) como verticalidade (em oposição à produção da horizontalidade em redes locais). Nesse sentido, cabe ainda investigar, em futuras pesquisas, exatamente de que forma a ação das UPPs vem interferindo na reconfiguração do território das favelas.

\section{Uma critica organizacional}

A análise dos discursos proferidos por membros do poder público desvela um reconhecido jogo de lutas sociais e mostra que o governo escolheu um lado nesse jogo. O ideal de levar a presença do Estado a um lugar antes esquecido é deixado para trás, em benefício de medidas de segurança que visam devolver a apropriação da cidade às classes mais ricas ("a gente tem uma cidade que tem segurança pra receber a Copa do Mundo, as Olimpíadas, e vários outros eventos"). Os moradores de favela são tratados de maneira preconceituosa e inferior, ao se orientar uma política pública apenas para a contenção dessa população, enquanto os espaços onde vivem são dominados e controlados pela polícia, em lugar de serem apropriados pelos próprios moradores.
Observando o ciclo da política pública das UPPs (BARDACH, 1993), conforme exposto anteriormente, as declarações sobre elas retratam, de maneira equivocada e subótima, como o problema a ser resolvido foi definido - a criminalidade na cidade do Rio de Janeiro, em lugar do problema de ausência de Estado em determinados territórios; além disso, evidenciou-se um modelo organizacional de implementação que desconsidera a complexidade organizacional - um processo burocrático de implantação, admitindo poder contar com um controle objetivo que efetivamente não existe; e, por fim, uma avaliação ineficiente que desconsidera a aplicação de um accountability real (cf. ETZIONI, 2009) - uma prestação de contas a uma parcela da sociedade sem considerar as relações sociais integradas e as obrigações de ação real direcionadas às comunidades. Dessa forma, as UPPs podem ser uma solução, mas permanece a pergunta: solução para quê?

O posicionamento declaradamente favorável à política de segurança em questão, sem o suporte de um processo de avaliação, e diante de sua recente implantação, deve ser questionado. Segundo Xavier (2008), a segurança pública apenas é alcançada quando o Estado fornece garantia e preservação dos direitos e liberdades individuais, e o que se observa é, ao contrário, a busca da simples ampliação dos mecanismos de dominação decorrente da instalação de organizações pacificadoras, representantes do Estado, nas favelas do Rio de Janeiro. O próprio Secretário de Segurança do Estado do Rio de Janeiro, José Mariano Beltrame, afirmou, em entrevista a um jornal, que as UPPs deveriam preparar o terreno para uma entrada mais efetiva do Estado, que não aconteceu: "O sucesso do projeto depende de investimentos maciços, e estes não estão sendo feitos na velocidade necessária" (O GLOBO, 2011).

As UPPs sufocaram a ação de organizações criminosas que dominavam e subjugavam diversas áreas da cidade. Essa conquista é positiva e não pode ser ignorada. No entanto, a tomada do território deveria ser apenas a primeira ação esperada do Estado, que se encontra em débito com as 280 mil pessoas (UPPRJ, 2011) que moram nesses espaços organizacionais onde já existe a UPP implantada. Mais uma vez, o Estado parece estar sucumbindo a demandas provocadas pelas dimensões econômicas do território e esquecendo sua função pública, que, diferentemente das funções privadas, deveria ser promovida segundo princípios sociais.

Essas novas formas organizacionais que se inserem nas favelas parecem negligenciar ou não assumir 
o protagonismo de sua influência na reconfiguração territorial, subaproveitando o seu potencial de gerar transformações sociais nesses espaços precários. Acreditamos que uma organização que buscasse a recuperação do espaço precário deveria ser catalisadora das contiguidades territoriais, fortalecendo as ligações locais em rede e favorecendo a chegada dos serviços de Estado faltantes (cf. SANTOS, 2009). Essa proposta, a ser aprofundada com futuras investigações, deve buscar diagnosticar as deficiências do espaço organizacional de favela com base no que ele é como território-lugar, e, a partir daí, sugerir intervenções de transformação nesse espaço.

\section{NOTA DOS AUTORES}

Daniel da S. Lacerda é bolsista da Coordenação de Aperfeiçoamento de Pessoal de Nível Superior (Capes) Processo no 1028/12-0.

\section{NOTA DA REDAÇÃO}

Este artigo participou do VII Encontro da Divisão de Estudos Organizacionais (ENEO), realizado em 2012 pelaAssociação Nacional de Pós-Graduação e Pesquisa em Administração (Anpad).

\section{REFERÊNCIAS}

BARDACH, E. Problemas de la definición de problemas en el análisis de políticas. In: BARDACH, E. Problemas públi$\cos y$ agenda de gobierno. México: Miguel Angel Porrua Editorial, 1993. p. 219-235

BEATO FILHO, C. C. Políticas públicas de segurança e a questão policial. São Paulo em Perspectiva, n. 4, v. 13, p.13-27, 1999.

BRANDÃO, C. A. Território e desenvolvimento: as múltiplas escalas entre o local e o global. São Paulo: Unicamp, 2007.

BURGOS, M. B. A utopia da comunidade: Rio das Pedras, uma favela carioca. 2 ed. Rio de Janeiro: Loyola, 2002.

CASTRO, I. E. . Instituições e territórios. Possibilidades e limites ao exercício da cidadania no Brasil. GEOSUL, v. 19, p. 16-32, 2003.

COSTA, V. G; NASCIMENTO, J. A. S. O conceito de favelas e assemelhados sob o olhar do IBGE, das prefeituras do
Brasil e da ONU. In: Encontro de Geógrafos da América Latina, 10, 2005, São Paulo. Anais. São Paulo: Universidade de São Paulo, 2005.

DELICATO, C. T. Cidades e favelas, pelos olhos de quem? Revista de Discentes do Programa de Pós-graduação em Ciências Sociais da Unesp Marília, n. 1, p. 39-51, 2007.

DEMATTEIS, G. O território: uma oportunidade para repensar a geografia. In: SAQUET, M. A. Abordagens e concepções sobre território. São Paulo: Expressão Popular, 2007.

DENALDI, R. Intervenção municipal em favelas: aprimoramento e limitações. In: Encontro Nacional da Associação Nacional de Pós-graduação e Pesquisa em Planejamento Urbano e Regional, 9, 2005, Salvador. Anais. Salvador: ANPUR, 2005.

ETZIONI, A. Concepções alternativas de accountability: O exemplo da gestão de saúde. In: HEIDEMANN, F. G; SALM, J. F. (Orgs) Políticas públicas e desenvolvimento: bases epistemológicas e modelos de análise. Brasília: Universidade de Brasília, 2009. p. 287-301.

FAIRCLOUGH N. Discurso e mudança social. Brasília: UnB, 2001.

GOULART, S. Uma abordagem ao desenvolvimento local inspirada em Celso Furtado e Milton Santos. Cadernos EBAPE.BR, v. 4, n. 3, p. 1-15, 2006.

GOULART, S; VIEIRA, M. M. F; COSTA, C. F; KNOPP, G. C. Articulações em rede e acontecimentos no território: subsídios teóricos para a formação de políticas públicas para o desenvolvimento. Cadernos EBAPE.BR, v. 8, n. 3, p. 388-403, 2010.

LEFEBVRE, H. O direito à cidade. São Paulo: Centauro, 2001.

MAGALHÃES, C. M. (Org). Reflexões sobre a análise crítica do discurso. Belo Horizonte: Faculdade de Letras da UFMG, 2001.

MARICATO, E. Favelas: um universo gigantesco e desconhecido. 2001 (não publicado). Disponível em: http:// www.usp.br/fau/depprojeto/labhab. Acesso em 19.01.2012.

NEVES, G. R. Territorialidade, desterritorialidade, novas territorialidades (algumas notas). In: SANTOS, M; SOUZA, 
M. A; SILVEIRA, M. L. (Orgs). Território: globalização e fragmentação. 5. ed. São Paulo: Hucitec, 2002.

OBSERVATÓRIO DE FAVELAS. O que é favela, afinal? In: SILVA, J. S. (Org). O que é favela, afinal? Rio de Janeiro: Observatório de Favelas do Rio de Janeiro, 2009.

O GLOBO. Beltrame quer pressa em investimentos sociais pós-UPPs. O Globo, Rio de Janeiro, 28.05.2011. Disponível em: http://oglobo.globo.com/rio/beltrame-quer-pressa-em-investimentos-sociais-pos-upps-nada-sobrevive-so-com-seguranca-2764060. Acesso em 02.02.2012.

OLIVEIRA, J. S. Repensando a questão das favelas. Revista Brasileira de Estudo de População, v. 2, n. 1, p. 9-30, 1985.

PINO, J. C. Labor in the favelas of Rio de Janeiro. Latin American Perspectives, v. 25, n. 2, The Urban Informal Sector, p. 18-40, 1998.

RAFFESTIN, C. Por uma geografia do poder. São Paulo: Ática, 1993.

RIO DE JANEIRO (Estado). Decreto no 42.787, de 06 de janeiro de 2011. Dispõe sobre a implantação, estrutura, atuação e funcionamento das unidades de polícia pacificadora (UPP) no estado do Rio De Janeiro e dá outras providências. Disponível em http://solatelie.com/cfap/html32/ decreto_42787_06-01-2011.html. Acesso em 19.08.2011.

SANTOS, M. A natureza do espaço: técnica e tempo, razão e emoção. 4. ed. São Paulo: Universidade de São Paulo, 2009.

SECCHI, L. Políticas públicas: conceitos, esquemas de análise, casos práticos. São Paulo: Cengage Learning, 2010.

SILVA, F. M. Unidade de Policiamento Pacificadora - UPP: um processo de democratização dos espaços favelados no Rio de Janeiro. In: Seminário Urbanismo na Bahia urbBA, 11, 2011. Anais. Universidade Federal da Bahia, 2011. p. $1-25$.

SOARES, L. E. Novas políticas de segurança pública. Estudos Avançados, v. 17, n. 47, p. 75-96, 2003.

SOUZA, C. Políticas públicas: uma revisão da literatura. Sociologias, ano 8, n. 16, p. 20-45, 2006.

SOUZA, M. A. A. Geografias da desigualdade: globalização e fragmentação. In: SANTOS, M; SOUZA, M. A; SILVEIRA,
M. L. (Orgs). Território: globalização e fragmentação. 5. ed. São Paulo: Hucitec, 2002.

STROZEMBERG, P. Alguém tem receio de ser multado na favela? In: SILVA, J. S. (Org). O que é favela, afinal? Rio de Janeiro: Observatório de Favelas do Rio de Janeiro, 2009.

UPPRJ. Conceito UPP: a polícia da paz. Disponível em: http://upprj.com/wp/?page_id=20. Acesso em 19.08.2011.

VALLADARES, L. A gênese da favela carioca: a produção anterior às ciências sociais. Revista Brasileira de Ciências Sociais, v. 15, n. 44, p. 5-34, 2000.

VALLADARES, L; FIGUEIREDO, A. Housing in Brazil: an introduction to recent literature. Bulletin of Latin American Research, v. 2, n. 2, p. 69-91, 1983.

VERGARA, S. C; VIEIRA, M. M. F. Sobre a dimensão tempo-espaço na análise organizacional. RAC-Revista de Administração Contemporânea, v. 9, n. 2, p. 103-120, 2005.

VIEIRA, M. M. F. ; GARROFÉ, P. H. S. O paradigma espaço-tempo: evolução e manipulação do sentido e do significado de espaço e de tempo nas organizações contemporâneas. Revista Eletrônica de Gestão Organizacional, v. 3, n. 1, p. 1-11, 2005.

VIEIRA, E. F; VIEIRA, M. M. F. Espaços econômicos: geoestratégia, poder e gestão do território. Porto Alegre: Sagra Luzzatto, 2003.

VIEIRA, M. M. F; CALDAS, M. P. Teoria crítica e pós-modernismo: principais alternativas à hegemonia funcionalista. RAE-Revista de Administração de Empresas, v. 46, n. 1, p. 59-70, 2006.

VILLANUEVA, L. F. A. Estudio introductorio. In: VILLANUEVA, L. F. A. La hechura de las politicas. México: Miguel Angel Porrua Editorial, 1992. p. 15-84.

XAVIER, A. Políticas Públicas De Segurança. Perspectivas Contemporâneas, Campo Mourão, v. 3, n. 2, p. 39-72, 2008. 